\title{
Association of glycemic control with progression of diabetic retinopathy in type 2 diabetes mellitus patients in Malaysia
}

\author{
Hasniza Zaman Huri ${ }^{1,2 *}$, Chua Chew Huey ${ }^{1}$, Norasyikin Mustafa ${ }^{3}$, Nor Fadhilah Mohamad ${ }^{4}$, \\ Tengku Ain Kamalden ${ }^{4}$
}

\begin{abstract}
${ }^{1}$ Department of Pharmacy, Faculty of Medicine, University of Malaya, Kuala Lumpur, Malaysia, ${ }^{2}$ Clinical Investigation Centre, University Malaya Medical Centre, Lembah Pantai Kuala Lumpur, ${ }^{3}$ Department of Ophthalmology, UiTM, UiTM Sungai Buloh Campus, Jalan Hospital, Sungai Buloh, Selangor Darul Ehsan, ${ }^{4}$ University of Malaya Eye Research Centre, Department of Ophthalmology, Faculty of Medicine, University of Malaya, Kuala Lumpur, Malaysia
\end{abstract}

\begin{abstract}
The risk of having microvascular complication is high among Type 2 Diabetes Mellitus (T2DM) patients. However, factors associated with the glycemic control and progression of diabetic retinopathy (DR) in T2DM patients is limited. This study aims to determine association between anti-diabetic agents, glycemic control and progression of diabetic retinopathy in a Malaysian population. A retrospective study conducted in a tertiary teaching hospital in Malaysia, from January 2009 until March 2014. This study enrolled 104 patients aged 40-84 years, with a mean age $63.12 \pm 9.18$ years. patients had non-proliferative diabetic retinopathy (NPDR, 77\%) and 35\% had proliferative diabetic retinopathy (PDR). Diabetic macula edema (DME) was present in $20 \%$ of NPDR patients, compared with $7 \%$ in PDR. Alpha-glucosidase inhibitor $(p=0.012)$, age $(p=0.014)$ and number of antidiabetic agents used $(p=0.015)$ were significantly associated with stages of diabetic retinopathy. Family history of T2DM $(p=0.039)$ was associated with DME. Identifying factors influencing the progression of diabetic retinopathy may aid in optimizing the therapeutic effects of anti-diabetic agents in T2DM patients.
\end{abstract}

Keywords: Type 2 Diabetes Mellitus. Anti-diabetic agents. Microvascular complication. Diabetic macula edema. Diabetic retinopathy. Malaysia.

\section{INTRODUCTION}

Diabetes mellitus is a chronic disorder that may cause acute or chronic long-term complications if it is not well controlled. One of the most common chronic microvascular complications is diabetic retinopathy (DR) (Priya, SrinivasaRao, Sharma, 2013). Diabetic retinopathy is classified into four stages, which are mild non-proliferative (NPDR), moderate NPDR, severe NPDR, and proliferative diabetic retinopathy (PDR). Most of Type 1 Diabetes Mellitus (T1DM) and Type 2 Diabetes Mellitus (T2DM) patients will develop DR after 20 years (Fong et al., 2004). The Malaysian Diabetes Eye Registry in 2007 reported $37 \%$ prevalence of DR in Malaysia (Goh, Ismail, Hussein, 2008; Ministry of Health

\footnotetext{
*Correspondence: H. Z. Huri. Department of Pharmacy, Faculty of Medicine, University of Malaya, 50603 Kuala Lumpur, Malaysia. Tel: +603 79676659. Fax: +603 7967 4964. E-mail: hasnizazh@um.edu.my
}

Malaysia, 2008). Factors associated with the progression of diabetic retinopathy in T2DM patients includes A1C level, co-morbidities, duration of DM diagnosed, age and gender (Chatziralli et al., 2010). In another study involving Chinese patients with DR and T2DM, positive correlations were found between DR and duration of diabetes, systolic blood pressure (SBP), diastolic blood pressure, glycated hemoglobin, glycated albumin, 24 hurinary albumin excretion, peripheral atherosclerosis (PA), diabetes nephropathy (DN), diabetic peripheral neuropathy and anemia (Bin-Bin et al, 2012).

Good glycemic control is associated in risk reduction in the progression of diabetic retinopathy. A $1 \mathrm{C}$ is a useful monitoring tool to evaluate the effectiveness of a therapeutic management plan for diabetes patients (Kahlon, Pathak, 2011). Study showed intensive glycemic control with A1C value $<6.5 \%$ has significantly $(p<0.003)$ reduced the progression of retinopathy. In a meta-analysis study, an intensive glycemic control reduced the risks of 
retinal photocoagulation or vitrectomy (OR 0.86; $95 \% \mathrm{CI}$ 0.75-0.98), macular edema (OR 0.65; $95 \%$ CI 0.43-0.99) and progression of retinopathy (OR $0.69 ; 95 \%$ CI 0.55 0.87) (Zhang et al., 2015). Thus, good glycemic control has proven to retard the progression of diabetic retinopathy in T2DM patients.

Although numerous studies have been found to assess the factors associated to DR in diabetes patients, none have addressed the potential association of the use of antidiabetics on DR progression in T2DM patients. In short, studies on association between different antidiabetic agents in T2DM patients with diabetic retinopathy and glycemic control are sparse and limited. Nevertheless, antidiabetic agents such as thiazolidinedione with good glycemic control have been proven to reduce the onset and risk of progression of retinopathy by $31 \%$ in a study (Ministry of Health Malaysia, 2008; Tschope et al., 2013). A study by Chung et al. (2016) reported that treatment with DPP4 inhibitors was the independent protective factor against the progression of DR, aside from improving glycemic control. Besides, the intensive diabetes management of using three or more daily insulin injections or a continuous subcutaneous insulin infusion for minimal to moderate NPDR has shown to reduce the risk of progression by $54 \%$ (95\% CI 39-66) by three years compare to conventional treatment with one or two injections of insulin (Fong et al., 2004).

The association between glycemic control, antidiabetic agents and severity of diabetic retinopathy has not been well investigated (Stratton et al., 2000). Therefore, the aims of this study are (i) to investigate the association between glycemic control in T2DM patient at different stages of DR, (ii) to investigate the factors that may be associated with glycemic control and DR in T2DM patients.

\section{MATERIAL AND METHODS}

\section{Study population and sampling frame}

The study population involved was Type 2 Diabetes Mellitus (T2DM) patients with diabetic retinopathy at University of Malaya Medical Center (UMMC). This observational, retrospective study was conducted from $1 \mathrm{st}$ January 2009 until 1 April 2014. Based on the calculation of Epi Info Program Version 7.0 (CDC, Clifton Rd. Atlanta, USA), the expected sample size for this study was 97 patients. If, the expected proportion of T2DM patients with DR was $60 \%$ and the confidence limit was $5 \%$. To obtain this sample size, the significant, $\alpha$, was set as 0.05 and the desired power of the study, $1-\beta$, was $80 \%$.

\section{Study design and procedures}

This study was conducted in University of Malaya Medical Centre (UMMC), which is one of the largest teaching hospitals in Malaysia with 1200 beds. This study was conducted in accordance with the Declaration of Helsinki and was approved by the UMMC Medical Ethics Committee (reference number 1031.5). The sample populations, which fulfilled the requirement of E11.0 until E11.8 in International Classification of Disease Tenth Revision (ICD-10), were identified via Hospital Information System (HIS). Subsequently, the medical records of patients were retrieved from Medical Records Office based on the inclusion and exclusion criteria. Convenient sampling technique was carried out to select the sample of population.

\section{Inclusion criteria:}

(1) Age 18 years and older.

(2) T2DM with DR.

(3) Patients that had A1C value.

\section{Exclusion criteria:}

(1) T2DM patients with diabetic retinopathy (DR) who were not prescribed with any antidiabetic agents.

A data collection form was used to record patients' information such as (1) demographics data i.e. age, gender, family history, stages of diabetic retinopathy, (2) history on the use of antidiabetic agents and concurrent medications for chronic illnesses (medications that are being used for more than 6 months) (3) co-morbidities (4) glycemic control (A1C and fasting blood glucose) - taken at least 3 months from the commencement of antidiabetic agents (5) laboratory results such as low density lipoprotein (LDL), triglyceride (TG), total cholesterol (TC), high density lipoprotein (HDL) and serum creatinine levels (Table I). The flowchart of methodology is shown in Figure 1.

\section{Statistical technique}

All the data collected were pooled and analyzed using IBM SPSS Statistics Version 22.0 (Armonk, New York, USA). Continuous data were expressed as mean \pm standard deviation while categorical data were expressed in term of percentage. Associations between independent categorical variables were examined using Pearson Chi-square test with Continuity Correction or Fisher Exact's test. The independent $t$-test was used to evaluate the different in mean between groups of continuous data. In this study, p-value of less than 0.05 was indicated as statistical significant. 


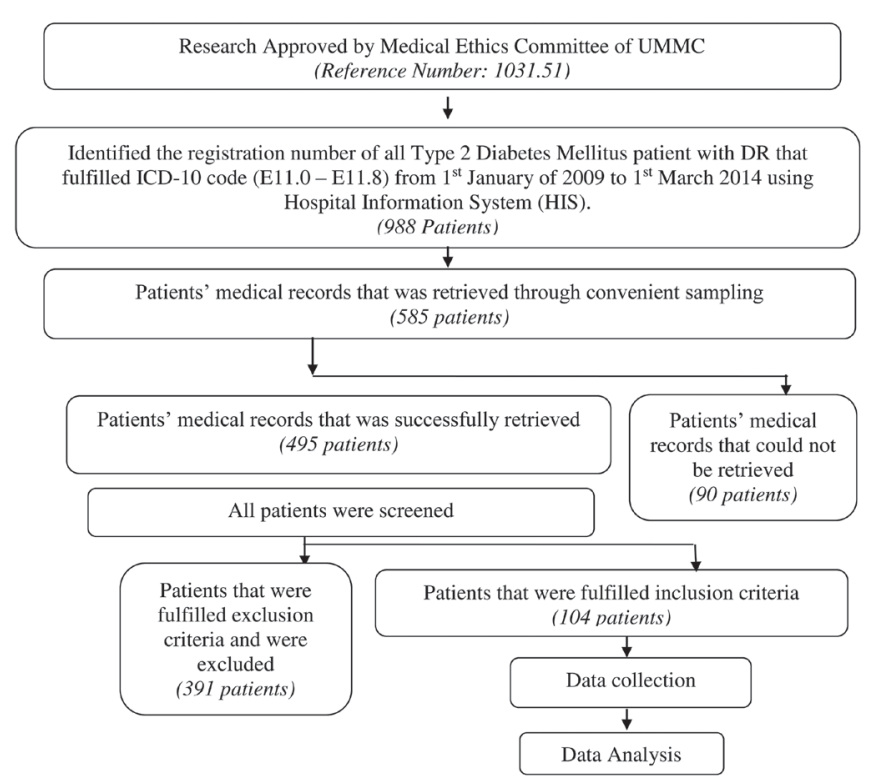

FIGURE 1 - Overview of methodology.

TABLE I - Definitions used in the study

\begin{tabular}{ll}
\hline Terms & Definition \\
\hline Targeted & $\begin{array}{l}\text { Patients with advanced micovascular } \\
\text { complications and extensive comorbid } \\
\text { Glycemic Control } \\
\text { conditions who achieved targeted goal of } \\
\text { glycated haemoglobin, HbA1C }<8 \% .\end{array}$ \\
\hline & $\begin{array}{l}\text { Chronic co-existing medical conditions } \\
\text { as listed in (Chronic Disease List) and }\end{array}$ \\
Comorbidities & $\begin{array}{l}\text { common medical conditions that may } \\
\text { present along with the T2DM patients } \\
\text { with DR }\end{array}$
\end{tabular}

Microvascular complication of diabetes

\begin{tabular}{|c|c|}
\hline $\begin{array}{l}\text { Diabetic } \\
\text { retinopathy, } \\
\text { DR }\end{array}$ & $\begin{array}{l}\text { mellitus, which is a progressive disease } \\
\text { that will cause blindness and visual } \\
\text { disability due to vessel damage at the } \\
\text { retina. In this study, the diagnosis of DR } \\
\text { was obtained from patient medical record. }\end{array}$ \\
\hline $\begin{array}{l}\text { Non-proliferative } \\
\text { diabetic } \\
\text { retinopathy, } \\
\text { NPDR }\end{array}$ & $\begin{array}{l}\text { A less severe stage in DR that shown in } \\
\text { fundoscopy of the presence of micro- } \\
\text { aneurysms with or without intraretinal } \\
\text { haemorrhages or definite venous beading } \\
\text { or intraretinal microvascular abnormalities } \\
\text { (Australian Diabetes Society, 2008) }\end{array}$ \\
\hline $\begin{array}{l}\text { Proliferative } \\
\text { diabetic } \\
\text { retinopathy, } \\
\text { PDR }\end{array}$ & $\begin{array}{l}\text { A severe stage in DR that shown } \mathrm{i} \\
\text { fundoscopy the presence of neovascu } \\
\text { larization with or without vitreous and } \\
\text { or preretinal haemorrhage (Australia } \\
\text { Diabetes Society, 2008) }\end{array}$ \\
\hline
\end{tabular}

Diabetic Macula Edema, DME
Presence of retinal thickening or hard exudates in posterior pole, near to center or distant from macula (Australian Diabetes Society, 2008)
The normality of data was assessed using the Shapiro-Wilk and Kolmogorov-Smirnov test. The data was normally distributed if both tests was not significant, $\mathrm{p}>0.05$.

\section{RESULTS}

104 T2DM patients with diabetic retinopathy were included in this study (Table II). The mean age of the patients was $63.12 \pm 9.18$ years, ranging from 40 to 84 years. The data on duration of T2DM was known in 96 patients $(92.3 \%)$, of which most were longer than 20 years. The median duration of T2DM was in the range of 16-20 years.

TABLE II - Demographic characteristics of patient $(\mathrm{N}=104)$

\begin{tabular}{lc}
\hline $\begin{array}{l}\text { Demographic } \\
\text { Characteristics }\end{array}$ & $\begin{array}{c}\text { Number of patient } \\
\text { (Percentage \%) }\end{array}$ \\
\hline Gender & \\
Male & $52(50.0)$ \\
\hline Age (years) & \\
18-64 & $56(53.8)$ \\
$>64$ & $48(46.2)$ \\
\hline Ethnicity & \\
Malay & $52(50.0)$ \\
Chinese & $27(26.0)$ \\
Indian & $24(23.1)$ \\
Others & $1(1.0)$ \\
\hline Duration of T2DM (years) & \\
$<1$ & $0(0.0)$ \\
1-5 & $4(3.8)$ \\
6-10 & $12(11.5)$ \\
$11-15$ & $24(23.1)$ \\
$16-20$ & $23(22.1)$ \\
$>20$ & $33(31.7)$ \\
Unknown & $8(7.7)$ \\
\hline Family History of T2DM & \\
Yes & $21(20.2)$ \\
No & $28(26.9)$ \\
Unknown & $55(52.9)$ \\
\hline BMI* & \\
Underweight( $<18.5)$ & $1(1.0)$ \\
Normal $(18.5-24.9)$ & $8(7.7)$ \\
Overweight $(25-29.9)$ & $8(7.7)$ \\
Obese $(\geq 30)$ & $2(1.9)$ \\
Unknown & $85(81.7)$ \\
\hline
\end{tabular}

Notes: Body Mass Index $=$ Weight $(\mathrm{kg}) \div\left[\operatorname{Height} \mathrm{x} \operatorname{Height}\left(\mathrm{m}^{2}\right)\right]$

\section{Clinical characteristics}

Patients' clinical characteristics are detailed in Table III. There were only four patients with DME alone while most coexisted with other stages of diabetic retinopathy (DR). The mean of A1C was $8.09 \pm 1.78 \%$ and Fasting 
Blood Glucose (FBG) was $7.52 \pm 4.17 \mathrm{mmol} / \mathrm{L}$. The range of $\mathrm{A} 1 \mathrm{C}$ value was $4.8 \%-13.4 \%$. Majority of the patients achieved the targeted $\mathrm{A} 1 \mathrm{C}$ below $8 \%$ (52.9\%). Uncommon comorbidities reported were hearing impairment, breast cancer, bipolar disorder, major depressive disorder, erectile dysfunction, and osteoporosis; whereas other concurrent medications listed were ketosteril, alendronate, tacrolimus, mycophenolate sodium, allopurinol and valproic acid.

\section{Profile of antidiabetic agents used in T2DM patients with DR}

Class of antidiabetic agents

Figure 2 shows the combination of antidiabetic agents and the common classes of antidiabetic used in the patients.

TABLE III - Clinical characteristic of patient ( $\mathrm{N}=104)$

\begin{tabular}{|c|c|c|}
\hline Clinical Characteristics & $\mathbf{N}$ & $\begin{array}{c}\text { Number of patient } \\
\text { (Percentage, } \% \text { ) }\end{array}$ \\
\hline \multicolumn{3}{|l|}{ Number of Antidiabetic } \\
\hline Agents used & 104 & \\
\hline One & & $48(46.2)$ \\
\hline Two & & $39(37.5)$ \\
\hline More than two & & $17(16.3)$ \\
\hline A1C & 104 & \\
\hline $\begin{array}{l}\text { Achieve targeted A1C } \\
(<8 \%)\end{array}$ & & $55(52.9)$ \\
\hline $\begin{array}{l}\text { Not achieve target A1C } \\
(\geq 8 \%)\end{array}$ & & $49(47.1)$ \\
\hline "Stages of DR and DME & 152 & \\
\hline Mild NPDR & & $30(28.8)$ \\
\hline Moderate NPDR & & $30(28.8)$ \\
\hline Severe NPDR & & $20(19.2)$ \\
\hline PDR & & $36(34.6)$ \\
\hline DME & & $36(34.6)$ \\
\hline \multicolumn{3}{|l|}{${ }^{\beta}$ Class of antidiabetic } \\
\hline agents used & 177 & \\
\hline Biguanide & & $49(47.1)$ \\
\hline Sulphonylurea & & 41(39.4) \\
\hline DPP4 inhibitor & & $4(3.8)$ \\
\hline Alpha-glucosidase & & $11(10.6)$ \\
\hline TZD & & $1(1.0)$ \\
\hline Insulin & & $71(68.3)$ \\
\hline
\end{tabular}

Insulin preparation and oral antidiabetic agents

Figure 3-6 illustrated the types of insulin agents used and the dosing agents of antidiabetics.

\section{Association of glycemic control with stages of DR and DME in T2DM patients}

The FBG mean was found to be statistically significant lower in T2DM patients with PDR $(\mathrm{t}=2.017$, $\mathrm{df}=102, \mathrm{p}=0.046)$. On the other hand, the other stages of DR and DME did not show any significant different in mean FBG levels (Table IV). Table V showed no statistically significant association between $\mathrm{A} 1 \mathrm{C}$ and the severity of DR as well as DME.

\begin{tabular}{lcc}
\hline Clinical Characteristics & N & $\begin{array}{c}\text { Number of patient } \\
\text { (Percentage, \%) }\end{array}$ \\
\hline BComorbidities & 276 & $100(96.2)$ \\
Hypertension & $24(23.1)$ \\
IHD & $19(18.3)$ \\
Stroke & $52(50)$ \\
Dyslipidemia & $60(57.5)$ \\
CKD & $4(3.8)$ \\
Asthma & $2(1.9)$ \\
Gout & $2(1.9)$ \\
Thyrotoxicosis & $2(1.9)$ \\
BPH & $2(1.9)$ \\
Atrial Fibrillation & $1(1.0)$ \\
Sleep disorder & $1(1.0)$ \\
Obesity & $7(6.7)$ \\
Others &
\end{tabular}

\begin{tabular}{lc}
\hline $\begin{array}{l}\text { Concurrent Medications } \\
\text { used }\end{array}$ & 367 \\
Antihypertensive & \\
Antihyperlipidemia & $100(96.2)$ \\
Antithrombolytic agent & $92(88.5)$ \\
Diuretic & $60(57.7)$ \\
Antidepressant & $43(41.3)$ \\
Antiangina & $4(3.8)$ \\
Thyroid product & $10(9.6)$ \\
Proton pump inhibitor & $3(2.9)$ \\
Hematinic & $2(1.9)$ \\
Supplement & $14(13.5)$ \\
Others & $26(25)$ \\
\hline
\end{tabular}

Notes: ${ }^{a}$ One patient may has more than one stage of diabetic retinopathy (DR) with or without diabetic macular edema (DME), or may have DME alone; ${ }^{\beta}$ One patient may has more than one comorbidities and antidiabetic agents.

Abbreviations: A1C, glycated haemoglobin concentration; CKD, Chronic Kidney Disease; DPP4 inhibitor, Dipeptidyl peptidase-4 enzyme inhibitors; IHD, Ischemic Heart Disease; NPDR, nonproliferative DR; PDR, proliferative DR; TZD, Thiazolidinediones; DME, diabetic macular edema. 


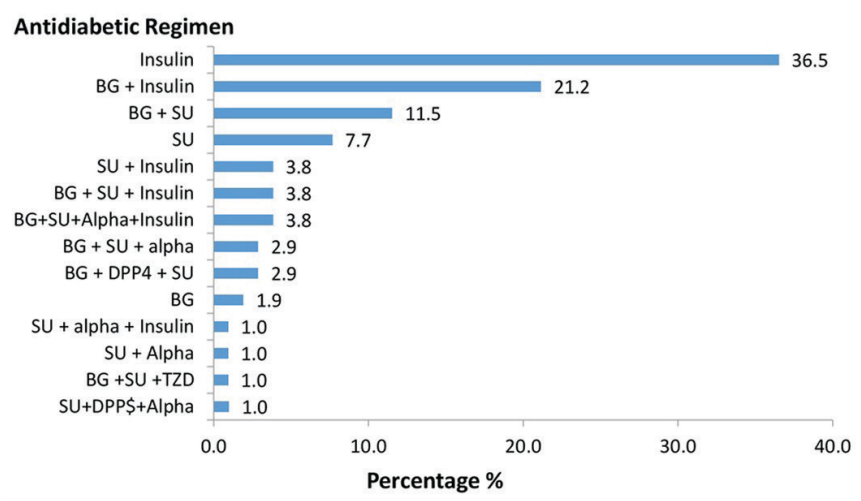

FIGURE 2 - Antidiabetic agents used in T2DM patient with DR $(\mathrm{N}=104)$; Alpha, alpha glucosidase; BG - biguanide; DPP4, Dipeptidyl peptidase-4 enzyme inhibitors; SU, sulphonylurea. peptidase-4 enzyme inhibitors; TZD, Thiazolidinediones.

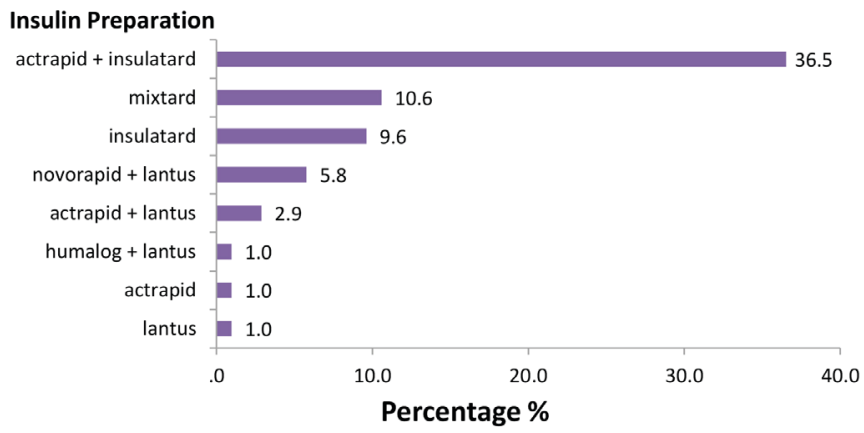

FIGURE 3 - Insulin preparation used for T2DM patient with $\mathrm{DR}(\mathrm{N}=104)$.

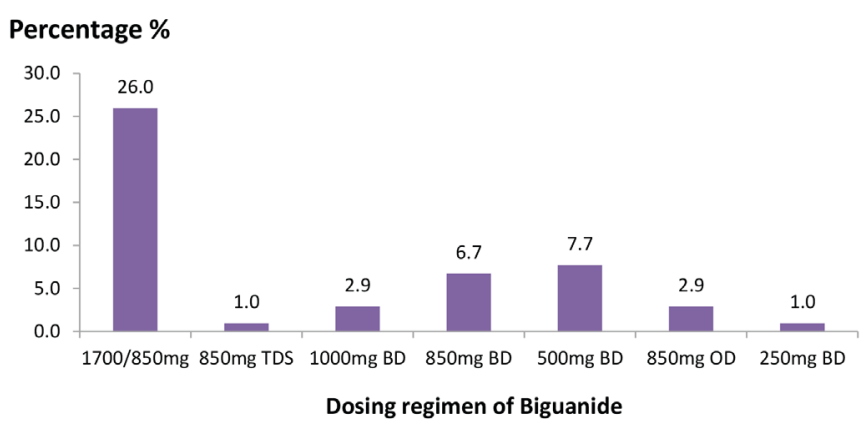

FIGURE 4 - Biguanide dosing agents for T2DM patient with $\mathrm{DR}(\mathrm{N}=104)$; $\mathrm{BD}$, twice daily; OD, once daily; TDS, three times daily.

\section{Antidiabetic agents}

\section{Association of stages of $D R$ and class of antidiabetic agents}

Table VI showed association of class of antidiabetics with the stages of DR and DME. The result showed that alpha-glucosidase inhibitor was the only class of antidiabetic agents that was statistically significant

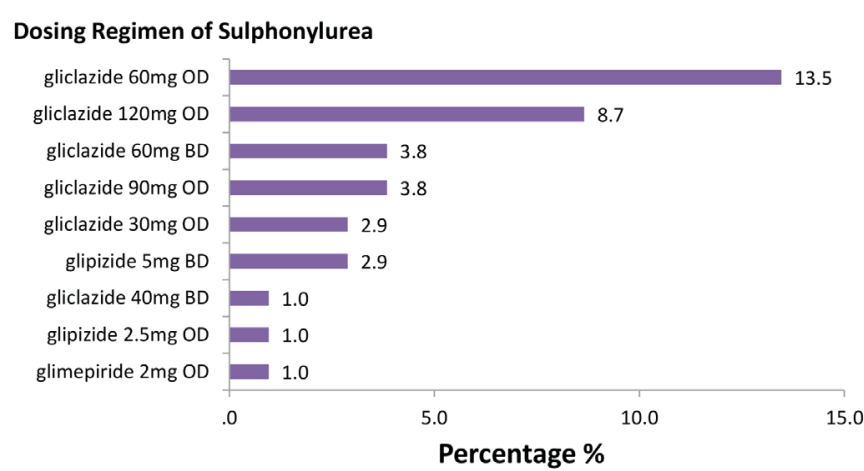

FIGURE 5 - Sulphonylurea dosing agents for T2DM patient with DR; BD, twice daily; OD, once daily; TDS, three times daily.

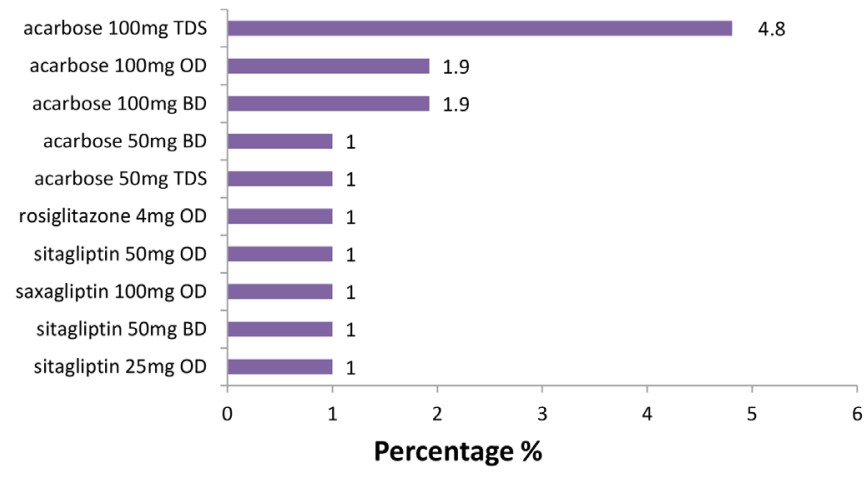

FIGURE 6 - Dosing agents for alpha-glucosidase, DPP4 and Thiazolidinediones; $\mathrm{BD}$, twice daily; $\mathrm{OD}$, once daily; TDS, three times daily.

associated with moderate NPDR, $\mathrm{p}=0.012$.

\section{Association of patients' demographic and clinical characteristics with glycemic control, stages of DR and DME}

\section{Factors Associated with Glycemic Control}

Referring to Table VII, ethnicity was statistically significant associated with glycemic control $\left(\chi^{2}=14.419\right.$, $\mathrm{df}=3, \mathrm{p}=0.002$ ).

\section{Factors associated with stages of DR and DME}

Table VIII showed all the demographic and clinical characteristic factors that had statistically significant association with severity of DR and diabetic macular edema. As shown in table 8, there was only one factor associated with each stage of DR and DME. Test revealed that, age was statistically significant associated with mild NPDR, $\left(\chi^{2}=6.026, \mathrm{df}=1, \mathrm{p}=0.014\right)$, number of antidiabetic agents used by patient was statistically significant associated with moderate NPDR, $\left(\chi^{2}=7.572\right.$, $\mathrm{df}=2, \mathrm{p}=0.023)$ and lastly family history of T2DM was 
TABLE IV - Association of FBG with severity of diabetic retinopathy (DR) and diabetic macular edema (DME) (N=104)

\begin{tabular}{lccc}
\hline${ }^{a}$ Stages of DR & Mean of FBG & Standard deviation & p-value \\
\hline Mild NPDR & 7.333 & 3.7211 & 0.776 \\
yes & 7.592 & 4.3625 & \\
no & 8.553 & 4.5521 & 0.107 \\
\hline Moderate NPDR & 7.097 & 3.9623 & \\
yes & & & 0.159 \\
no & 8.700 & 4.1294 & \\
\hline Severe NPDR & 7.236 & 4.1561 & $* 0.046$ \\
yes & & & \\
no & 6.400 & 3.7535 & \\
PDR & 8.109 & 4.2937 & \\
yes & & & \\
no & 7.778 & 4.1978 & 0.645 \\
\hline DME & 7.379 & 4.1820 & \\
yes & & & \\
no & & & \\
\hline
\end{tabular}

Notes: ${ }^{\alpha}$ One patient may has more than one stage of DR with or without DME, or may have DME alone. Mild NPDR $(\mathrm{n}=30)$, moderate NPDR $(n=30)$, severe NPDR $(n=20)$, PDR $(n=36)$, DME $(n=36)$, *Statistically significant level set at $p<0.05$.

TABLE V - Association of A1C with severity of diabetic retinopathy (DR) and diabetic macular edema (DME)

\begin{tabular}{|c|c|c|c|}
\hline \multirow{2}{*}{${ }^{B}$ Stages of DR } & \multicolumn{2}{|c|}{$\mathrm{A} 1 \mathrm{C} \%$} & \multirow{2}{*}{$p=$ value } \\
\hline & $<8$ & $\geq 8$ & \\
\hline \multicolumn{4}{|l|}{ Mild NPDR } \\
\hline yes & $18(17.3 \%)$ & $12(11.5 \%)$ & \\
\hline no & $37(53.6 \%)$ & $37(35.6 \%)$ & $0.478^{\mathrm{a}}$ \\
\hline \multicolumn{4}{|c|}{ Moderate NPDR } \\
\hline yes & $13(12.5 \%)$ & $17(16.3 \%)$ & \\
\hline no & $42(40.4 \%)$ & $32(30.8 \%)$ & $0.305^{\mathrm{a}}$ \\
\hline \multicolumn{4}{|l|}{ Severe NPDR } \\
\hline yes & $7(6.7 \%)$ & $13(12.5 \%)$ & \\
\hline no & $48(46.2 \%)$ & $36(34.6 \%)$ & $0.125^{\mathrm{a}}$ \\
\hline \multicolumn{4}{|l|}{$\overline{\text { PDR }}$} \\
\hline yes & $22(21.2 \%)$ & $36(34.6 \%)$ & \\
\hline no & $33(31.7 \%)$ & $68(65.4 \%)$ & $0.309^{\mathrm{a}}$ \\
\hline \multicolumn{4}{|l|}{ DME } \\
\hline yes & $19(18.3 \%)$ & $17(16.3 \%)$ & \\
\hline no & $36(34.6 \%)$ & $32(30.8 \%)$ & $1.000^{\mathrm{a}}$ \\
\hline
\end{tabular}

Notes: ${ }^{a}$ Computed using Continuity Correction; ${ }^{\beta}$ One patient may has more than one stage of DR with or without DME, or may have DME alone. Mild NPDR $(n=30)$, moderate NPDR $(n=30)$, severe NPDR $(n=20)$, PDR $(n=36)$, DME $(n=36)$

significantly associated with diabetic macular edema, $\left(\chi^{2}\right.$ $=6.477, \mathrm{df}=2, \mathrm{p}=0.039$ ).

\section{DISCUSSION}

\section{Association of glycemic control with stages of DR and DME}

Poor glycemic control is one of the important risk factors causing the onset and progression of diabetic retinopathy (DR). Severity of diabetic retinopathy was found to be significantly associated with $\mathrm{A} 1 \mathrm{C}$ levels with $\mathrm{p}=0.001$ (Chatziralli et al., 2010). A decrease in A1C is associated with a $25 \%$ lower risk of DR progression of DR in Type 2 Diabetic Mellitus (T2DM) patient (Mohamed, Gillies, Wong, 2007). A landmark study looking at complications of T2DM (UKPDS) showed that the risk of onset and progression of any stages of diabetic retinopathy 
TABLE VI - Association of stages of diabetic retinopathy (DR) with class of antidiabetic agents

\begin{tabular}{|c|c|c|c|}
\hline \multirow{2}{*}{ Class of antidiabetic agents } & \multicolumn{2}{|c|}{ Moderate NPDR } & \multirow{2}{*}{ p-value } \\
\hline & yes & no & \\
\hline \multicolumn{4}{|l|}{ Insulin } \\
\hline yes & $22(21.2 \%)$ & $8(7.7 \%)$ & \\
\hline no & $49(47.1 \%)$ & $25(24.0 \%)$ & $0.636^{\mathrm{a}}$ \\
\hline \multicolumn{4}{|l|}{ Biguanide } \\
\hline yes & $16(15.4 \%)$ & $33(31.7 \%)$ & \\
\hline no & $14(13.5 \%)$ & $41(39.4 \%)$ & $0.554^{\mathrm{a}}$ \\
\hline \multicolumn{4}{|l|}{ Sulphonylurea } \\
\hline yes & $14(13.5 \%)$ & $27(26.0 \%)$ & \\
\hline no & $16(15.4 \%)$ & $47(45.2 \%)$ & $0.459^{\mathrm{a}}$ \\
\hline \multicolumn{4}{|l|}{ Alpha-glucosidase inhibitor } \\
\hline yes & $7(6.7 \%)$ & $4(3.8 \%)$ & \\
\hline no & $23(22.1 \%)$ & $70(67.3 \%)$ & $* 0.012^{\mathrm{b}}$ \\
\hline \multicolumn{4}{|l|}{ DPP4 inhibitor } \\
\hline yes & $1(1.0 \%)$ & $3(2.9 \%)$ & \\
\hline no & $29(27.9 \%)$ & $71(68.3 \%)$ & $0.636^{\mathrm{a}}$ \\
\hline
\end{tabular}

Notes: ${ }^{\mathrm{a} C}$ Computed using Continuity Correction; ${ }^{\mathrm{b}}$ Computed using Fisher's Exact Test.

Abbreviations: DPP4 inhibitor, Dipeptidyl peptidase-4 enzyme inhibitors; NPDR, non-proliferative DR

was strongly and significantly associated with glycemic control of A1C more than 7.5\% (Stratton et al., 2001). There is a study which showed that a mean of targeted glycemic control $<8.5 \%$ was significantly associated with reduction of risk of progression in DR (Brinchmann-Hansen et al., 1992), although there was no significantly association between glycemic control, A1C with the severity of DR and DME shown in this study. However, the result of this study shows that, majority of T2DM patients with DR did not achieved targeted glycemic control except for mild NPDR. Thus, there might be some benefits of good glycemic control in reducing the risk of onset and progression of DR.

The mean fasting blood glucose was lower in the PDR compared to others stages of diabetic retinopathy and DME. This result contradicts a previous study by Teuscher et al which showed that the incidence of PDR was higher in patients with $\mathrm{FBG}$ of more than $14.5 \mathrm{mmol} / \mathrm{L}$, as well as NPDR (Teuscher, Schnell, Wilson, 1988). Besides that, a study conducted in United Kingdom reported that, mean fasting blood glucose, $8.51 \mathrm{mmol} / \mathrm{L}$ with intensive therapy that decreased the mean of FBG around $1.2 \mathrm{mmol} / \mathrm{L}$ was associated with reduction in the progression of DR (Patel et al., 2008). Fasting blood glucose is different from glycated haemoglobin concentration as it can be varied, affected by diet taken and fasting state before the test done. Therefore, the discrepancy might be because there was variation in the way of data collection. Moreover, the data for study conducted by Teuscher, Schnell and Wilson (1998) and Patel et al. (2008) was based on the baseline
FBG before and after the onset or progression of diabetic retinopathy.

\section{Antidiabetic agents}

\section{Association of stages of $D R$ and class of antidiabetic agents}

Class of antidiabetic agents alpha-glucosidase inhibitor, acarbose was significantly associated with the moderate non-proliferative diabetic retinopathy (NPDR). Acarbose used was strongly and significantly associated with presence of moderate NPDR as shown in study. Animal study showed that, acarbose use might lessen the effect on the development of retinopathy in Zucker Diabetic Fatty rats (Yang et al., 2000). On the other hand, a study showed, acarbose was associated with positive effect of postprandial hyperglycemia (Derosa, Maffioli, 2012). Moreover, two cohort studies agreed that, increase in postprandial plasma glucose was associated with increasing risk of progression of diabetic retinopathy (DR) (Mannucci et al., 2012). Therefore, acarbose might possibly indirectly cause reduction in the risk of progression of DR due to its efficacy proven in reduction of postprandial plasma glucose. However, the result of this study was varied from the finding in those studies. This was probably due to small sample size and the results cannot be generalized as there was only $10.6 \%$ of patients took alpha-glucosidase inhibitor antidiabetic agents as combination therapy. 
TABLE VII - Association between A1C with demographic and clinical characteristics

\begin{tabular}{|c|c|c|c|}
\hline \multirow{2}{*}{$\begin{array}{l}\text { Demographic and Clinical } \\
\text { Characteristic }\end{array}$} & \multicolumn{2}{|c|}{ A1C \% } & \multirow{2}{*}{ p-value } \\
\hline & $<8$ & $\geq 8$ & \\
\hline \multicolumn{4}{|l|}{ Age } \\
\hline elderly $(>64)$ & $28(26.9 \%)$ & $20(19.2 \%)$ & \\
\hline non-elderly (18-64) & $27(26 \%)$ & $29(27.9 \%)$ & $0.405^{\mathrm{a}}$ \\
\hline \multicolumn{4}{|l|}{ Gender } \\
\hline Male & $31(29.8 \%)$ & $21(20.2 \%)$ & \\
\hline Female & $24(23.1 \%)$ & $28(26.9 \%)$ & $0.239^{\mathrm{a}}$ \\
\hline \multicolumn{4}{|l|}{ Ethnicity } \\
\hline Malay & $24(23.1 \%)$ & $28(26.9 \%)$ & \\
\hline Chinese & $22(21.2 \%)$ & $5(4.8 \%)$ & \\
\hline Indian & $9(8.7 \%)$ & $15(14.4 \%)$ & \\
\hline Others & $0(0.0 \%)$ & $1(1.0 \%)$ & $* 0.002^{\mathrm{b}}$ \\
\hline \multicolumn{4}{|l|}{$\overline{\text { BMI }}$} \\
\hline underweight & $1(1.0 \%)$ & $0(0.0 \% 0$ & \\
\hline normal & $3(2.9 \%)$ & $5(4.8 \%)$ & \\
\hline overweight & $6(5.8 \%)$ & $2(1.9 \%)$ & \\
\hline obese & $2(1.9 \%)$ & $0(0.0 \%)$ & \\
\hline unknown & $43(41.3 \%)$ & $42(40.4 \%)$ & $0.170^{\mathrm{b}}$ \\
\hline \multicolumn{4}{|l|}{ Duration of T2DM } \\
\hline $1-5$ & $1(1.0 \%)$ & $3(3.1 \%)$ & \\
\hline $6-10$ & $5(5.2 \%)$ & $7(7.3 \%)$ & \\
\hline $11-15$ & $10(10.4 \%)$ & $14(14.6 \%)$ & \\
\hline $16-20$ & $12(12.5 \%)$ & $11(11.5 \%)$ & \\
\hline$>20$ & $23(24.0 \%)$ & $10(10.4 \%)$ & $0.137^{\mathrm{b}}$ \\
\hline \multicolumn{4}{|l|}{ Family History of T2DM } \\
\hline yes & $10(9.6 \%)$ & $11(10.6 \%)$ & \\
\hline no & $12(11.5 \%)$ & $16(15.4 \%)$ & \\
\hline unknown & $33(31.7 \%)$ & $22(21.2 \%)$ & $0.289^{c}$ \\
\hline \multicolumn{4}{|l|}{ Number of antidiabetic } \\
\hline agents & $31(29.8 \%)$ & $17(16.3 \%)$ & \\
\hline 1 & $17(16.3 \%)$ & $22(21.2 \%)$ & \\
\hline 2 & $7(6.7 \%)$ & $10(9.6 \%)$ & $0.085^{c}$ \\
\hline$>2$ & & & \\
\hline
\end{tabular}

Notes: ${ }^{\mathrm{a}}$ Computed by using Continuity Correction; ${ }^{\mathrm{b}}$ Likelihood Ratio $;{ }^{\mathrm{c}}$ Pearson Chi-square; ${ }^{*}$ Statistically significant $(\mathrm{p}<0.05)$

Abbreviations: BMI, Body Mass Index; T2DM, type 2 diabetes mellitus

\section{Association of demographic and clinical characteristics factors with glycemic control, stages of DR and DME}

\section{Factors associated with glycemic control}

Ethnicity was the only demographic characteristics that resulted in significantly associated with the glycemic control. Moreover, it was found that the Indian ethnic group was strongly and significantly associated with not achieved the targeted glycemic control compared with other ethnic groups. This concurs with a study done by Sazlina et al. (2015) that found Malay (OR 1.53, 95\% CI 1.41-1.66) and Indian (OR 1.32, 95\% CI 1.19-1.46) ethnicities were predictors of poor glycemic control owing to their greater insulin resistance state (Khoo et al., 2011). Higher state of insulin resistance poses the risk of patients getting chronic complications of T2DM as shown in this study in which all patients had DR. Thus, a more comprehensive approach targeting the lifestyle intervention such as diet and exercise should be focused to achieve a better glycemic control.

Factors associated with stages of diabetic retinopathy and diabetic macular edema

This study found out that, age was the factors that significantly associated with mild non-proliferative 
TABLE VIII - Factors of demographic and clinical characteristic that significantly associated with stages of diabetic retinopathy (DR) and diabetic macular edema (DME)

\begin{tabular}{|c|c|c|c|}
\hline \multirow{3}{*}{$\begin{array}{l}\text { Demographic and Clinical } \\
\text { Characteristic }\end{array}$} & \multicolumn{2}{|c|}{${ }^{\beta}$ Stages of DR and DME } & \multirow{3}{*}{ p-valuc } \\
\hline & \multicolumn{2}{|c|}{ Mild NPDR } & \\
\hline & yes & no & \\
\hline \multicolumn{4}{|l|}{ Age } \\
\hline Elderly & $20(19.2 \%)$ & $28(26.9 \%)$ & \\
\hline \multirow[t]{3}{*}{ Non-elderly } & $10(9.6 \%)$ & $46(44.2 \%)$ & $* 0.014^{\mathrm{a}}$ \\
\hline & \multicolumn{2}{|c|}{ Moderate NPDR } & \\
\hline & yes & no & \\
\hline \multicolumn{4}{|l|}{ Number of antidiabetic agents } \\
\hline 1 & $12(11.5 \%)$ & $36(34.6 \%)$ & \\
\hline 2 & $8(7.7 \%)$ & $31(29.8 \%)$ & \\
\hline \multirow[t]{3}{*}{$>2$} & $10(9.6 \%)$ & $7(6.7 \%)$ & $* 0.015^{\mathrm{c}}$ \\
\hline & \multicolumn{2}{|c|}{ DME } & \\
\hline & yes & no & \\
\hline \multicolumn{4}{|l|}{ Family History of T2DM } \\
\hline yes & $11(10.6 \%)$ & $10(9.6 \%)$ & \\
\hline no & $5(4.8 \%)$ & $23(22.1 \%)$ & \\
\hline unknown & $20(19.2 \%)$ & $35(33.7 \%)$ & $* 0.039^{\mathrm{b}}$ \\
\hline
\end{tabular}

Notes: ${ }^{\mathrm{a}}$ Computed by using Continuity Correction; ${ }^{\mathrm{b}}$ Pearson Chi Square; ${ }^{\mathrm{c}}$ Likelihood Ratio; *Statistically significant $(\mathrm{p}<0.05)$; ${ }^{\beta}$ One patients may have more than one stages of DR and DME.

Abbreviations: antiD, antidiabetic agents; DME, diabetic macular edema, NPDR, non-proliferative DR; T2DM, type 2 diabetes mellitus.

DR (NPDR). More specifically, elderly was found to be strongly significant associated with the presence of mild NPDR. This finding was agreed by an India study conducted at urban which showed that, the risk of having diabetic retinopathy was significantly associated with group of patients aged more than 50 years compared with aged 30-49, with odd ratio of 7.78, (95\% $\mathrm{Cl} 2.92-20.73)$ (Dandona et al., 1999). A large study from UKPDS 50 also suggested that older age was significantly associated with progression of DR (Stratton et al., 2001). Therefore, the risk of onset of DR in elderly would be high might also due to the long duration since diagnosed Diabetes Mellitus (DM) compared with those with shorter duration of DM (Leske et al., 2005).

The number of antidiabetic agents taken appeared to be another factor that was significantly associated with stages of DR, which was moderate non-proliferative Diabetic Retinopathy (NPDR). The finding showed that, more than two antidiabetic agents taken was strongly and significantly associated with the presence of moderate NPDR. To date, medication adherence is always the concern for diabetes mellitus patients (Hutchins et al., 2011). Thus, studies reported that, fixed dose combinations antidiabetic agents had better medication adherence and glycemic control compared with co-administered dual therapy of antidiabetic agents (Han et al., 2012). Furthermore, there were no studies that specifically discuss about the number of antidiabetic agents with onset and progression of NPDR. But, the explanation for the finding in this study might be due to the uncontrolled glycemic control caused by medication non-compliance. A study showed that, number of antidiabetic agents was significantly associated with glycemic control (Guillausseau, 2005). Then, it might indirectly cause the deterioration of DR. Moreover, there was no data recorded regarding the medication compliance condition for the patients.

Apart from that, family history of T2DM was found to be significantly associated with diabetic macular edema (DME). In addition, the presence of family history of T2DM was strongly and significantly associated with the presence of DME. This finding was aligned with a multicenter prospective descriptive study which reported that, there was as high as $86 \%$ of study subjects with family history of diabetes mellitus diagnosed with macular pattern dystrophy while only $8 \%$ of the patients being diagnosed with diabetic retinopathy (Guillausseau et al., 2001). Therefore, genetic disposition might cause the 
development of macular dystrophy. However, the results could not be generalized as there were more than half of the patients who did not have their family history illness recorded.

\section{CONCLUSION}

Most of the patients with diabetic retinopathy did not achieved targeted glycemic control, A1C $<8 \%$ except for mild non-proliferative Diabetic Retinopathy (NPDR). No significant association was found between glycemic control and stages of Diabetic retinopathy. Acarbose was found to be associated with moderate NPDR.

Elderly and number of antidiabetic agents taken were being identified as factors associated with the stages of DR. Identifying factors influencing the progression of diabetic retinopathy may aid in optimizing the therapeutic effects of anti-diabetic agents in T2DM patients.

\section{ACKNOWLEDGMENTS}

The authors would like to thank the University of Malaya, Malaysia (RP024A-14HTM, RP006B-13HTM and RP033-14HTM) for financial and technical support.

\section{DISCLOSURE} work.

The author reports no conflicts of interest in this

\section{REFERENCES}

Bin-Bin H, Li W, Yun-Juan G, Jun-Feng H, Ming L, YuXiang L, et al. Factors associated with diabetic retinopathy in chinese patients with Type 2 Diabetes Mellitus. Int J Endocr. 2012;2012:157940.

Brinchmann-Hansen O, Dahl-Jørgensen K, Sandvik L, Hanssen KF. Blood glucose concentrations and progression of DR: the seven year results of the Oslo study. BMJ. 1992;304(6818):1922.

Chatziralli IP, Sergentanis TN, Keryttopoulos P, Vatkalis N, Agorastos A, Papazisis L. Risk factors associated with DR in patients with diabetes mellitus type 2. BMC Res Notes. 2010;3(1):1-4.

Chung YR, Park SW, Kim JW, Kim JH, Lee K. Protective effects of Dipeptidyl Peptidase-4 inhibitors on progression of diabetic retinopathy in patients with Type 2 Diabetes. Retina. 2016;36(12):2357-2363.
Dandona L, Dandona R, Naduvilath TJ, McCarty CA, Rao GN. Population-based assessment of DR in an urban population in southern India. Br J Ophthalmol. 1999;83(8):937-940.

Derosa G, Maffioli P. Efficacy and safety profile evaluation of acarbose alone and in association with other antidiabetic agents: a systematic review. Clin Ther. 2012;34(6):1221-1236.

Fong DS, Aiello L, Gardner TW, King GL, Blankenship G, Cavallerano JD, et al. Retinopathy in Diabetes. Diabetes Care. 2004;27(1):s84-s87.

Goh PP, Ismail M, Hussein E. Status of DR among diabetics registered to the Diabetic Eye Registry, National Eye Database, 2007. Med J Malaysia. 2008;63(Suppl C):24-28.

Guillausseau PJ, Massin P, Dubois-LaForgue D1, Timsit J, Virally M, Gin H, et al. Maternally inherited diabetes and deafness: a multicenter study. Ann Intern Med. 2001;134(9):721728.

Guillausseau PJ. Impact of compliance with oral antihyperglycemic agents on health outcomes in Type 2 Diabetes Mellitus. Treat Endocrinol. 2005;4(3):167-175.

Han S, Iglay K, Davies MJ, Zhang Q, Radican L. Glycemic effectiveness and medication adherence with fixed-dose combination or coadministered dual therapy of antihyperglycemic agents: a meta-analysis. (Curr Med Res Opin. 2012;28(6):969-977.

Hutchins V, Zhang B, Fleurence RL, Krishnarajah G, Graham J. A systematic review of adherence, treatment satisfaction and costs, in fixed-dose combination agents in type 2 diabetes. Curr Med Res Opin. 2011;27(6):1157-1168.

Kahlon AS, Pathak R. Patterns of glycemic control using glycosylated hemoglobin in diabetics. J Pharm Bioall Sci. 2011;3(3):324-328.

Khoo CM, Sairazi S, Taslim S, Gardner D, Wu Y, Lee J, van Dam RM, Shyong Tai E. Ethnicity modifies the relationships of insulin resistance, inflammation, and adiponectin with obesity in a multiethnic Asian population. Diabetes Care. 2011;34(5):11206.

Leske MC, Wu SY, Hennis A, Hyman L, Nemesure B, Yang L, Schachat AP. Hyperglycemia, blood pressure, and the 9-year incidence of DR: the barbados eye studies. Ophthalmology. 2005;112(5):799-805. 
Mannuci E, Monami M, Lamanna C, Adalsteinsson J. Postprandial glucose and diabetic complications: systematic review of observational studies. Acta Diabetol. 2012;49(4):307-314.

Ministry of Health Malaysia. Clinical Practice guideline: Screening of DR. 2008. Available from: www.moh.gov.my/ attachments/6601.pdf.

Mohamed Q, Gillies MC, Wong TY. Management of diabetic retinopathy a systematic review. JAMA. 2007;298(8):902-916.

Patel A, MacMahon S, Chalmers J, Neal B, Billot L, Woodward $\mathrm{M}$, et al. Intensive blood glucose control and vascular outcomes in patients with type 2 diabetes. N Engl J Med. 2008;358:25602572.

Priya PV, SrinivasaRao A, Sharma JVC. DR can lead to complete blindness. 2013. Available from: https://www.researchgate.net/ publication/282609747_Diabetic_Retinopathy___Can_Lead_ to_Complete_Blindness.

Sazlina SG, Mastura I, Cheong AT, Bujang Mohamad A, Jamaiyah H, et al. Predictors of poor glycaemic control in older patients with type 2 diabetes mellitus. Singapore Med J. 2015;56(5):284-90.

Stratton IM, Adler AI, Neil HAW, Matthews DR, Manley SE, Cull CA, et al. Association of glycaemia with macrovascular and microvascular complications of type 2 diabetes (UKPDS 35): prospective observational study. BMJ. 2000;321(7258):405412.
Stratton IM, Kohner EM, Aldington SJ, Turner RC, Holman RR, Manley SE, et al. UKPDS 50: Risk Factors for incidence and progression of retinopathy in Type 2 Diabetes over 6 years from diagnosis. Diabetologia. 2001;44(2):156-163.

Teuscher A, Schnell H, Wilson PW. Incidence of DR and relationship to baseline plasma glucose and blood pressure. Diabetes Care. 1988;11(3):246-251.

Tschope D, Hanefeld M, Meier JJ, Gitt AK, Halle M, Braniage P, Schumm Draeger P. The role of co-morbidity in the selection of antidiabetic pharmacotherapy in type 2 diabetes. Cardiovasc Diabetol. 2013;12(1):62.

Yang YS, Danis RP, Peterson RG, Dolan PL, Wu YQ. Acarbose Partially Inhibits Microvascular Retinopathy in the Zucker Diabetic Fatty Rat (ZDF/GmiTM-fa). J Ocul Pharmacol Ther. 2000;16(5):471-479.

Zhang X, Zhao J, Zhao T, Liu H. Effects of intensive glycemic control in ocular complications in patients with type 2 diabetes: a meta-analysis of randomized clinical trials. Endocrine. 2015;49(1):78-79.

Received for publication on $25^{\text {th }}$ August 2017 Accepted for publication on $15^{\text {th }}$ December 2017 